\title{
Non-verbal victims in the adversarial criminal process: communication, competency, and credibility
}

JONATHAN DOAK

Nottingham Law School, Nottingham Trent University

AND

LAURAN DOAK

Sheffield Institute of Education, Sheffield Hallam University

\begin{abstract}
Research consistently shows that persons with learning disabilities are more likely to be victims of crime. For such victims, engaging with the criminal justice system may be fraught with difficulties given the expectation that victims should normally articulate verbally and with fluency both their testimony and their views on issues pertaining to the justice process itself. Grounded in the principle of orality and often likened to a system of gladiatorial combat, adversarial justice systems have a poor track record of hearing the voices of victims of crime who have learning disabilities. However, recent years have witnessed an attitudinal shift towards meeting the needs of victims who require communication support; with legal and policy reforms introduced across multiple jurisdictions designed to enable more effective participation in the justice process. Augmentative and alternative communication could constitute an important support mechanism to enable and empower victims of crime who would struggle to express themselves verbally in the courtroom; yet these alternative forms of voice are alien to the oral tradition and sit uneasily within the priority traditionally afforded to adversarial questioning techniques.
\end{abstract}

Keywords: victims; witnesses; disabilities; communication; competency; credibility; augmentative and alternative communication

\section{Introduction}

$\mathrm{T}$ There is a growing corpus of literature documenting the specific difficulties experienced by victims with learning disabilities within the criminal process. ${ }^{1}$ Disabled persons are at a considerably higher risk of victimisation generally, and disability hate crime and sexual offences in particular. ${ }^{2}$ They are often highly dependent on paid or family caregivers for assistance in multiple domains including managing personal finances, personal (intimate) care and social care which may create opportunities for abusers; and people with learning

1 See e.g. Jessica Jones, 'Persons with Intellectual Disabilities in the Criminal Justice System: Review of Issues' (2007) 51 International Journal of Offender Therapy and Comparative Criminology 723; Shane Kilcommins et al, An International Review of Legal Provisions and Supports for People with Disabilities as Victims of Crime (Irish Council of Civil Liberties 2014); Chih Hoong Sin et al, Disabled People's Experiences of Targeted violence and Hostility (Equality and Human Rights Commission 2009).

2 See e.g. Lisa Jones et al, 'Prevalence and Risk of Violence against Children with Disabilities: A Systematic Review and Meta-analysis of Observational Studies' (2012) 380 The Lancet 899; Sue Ralph et al, 'Disability Hate Crime: Persecuted for Difference' (2016) 43(3) British Journal of Special Education 215. 
disabilities may be less likely to realise the nature of the offence and/or report it. ${ }^{3}$ This article focuses on the issues facing such victims as they are often the only sources of evidence, though much of what we argue is equally applicable to non-victim witnesses (including defendants). Questioning techniques and the stress of the investigation can disorientate many witnesses; they may appear to be inarticulate or may make inconsistent statements. Perceptions that they are incapable of providing credible evidence or that they are unlikely to cross the competency threshold (sometimes held by victims themselves) mean that many complaints are not made, not taken seriously, or fall to the wayside before they reach court. ${ }^{4}$

This article explores the participatory barriers facing a specific sub-group of learning disabled witnesses, namely those who might be described as 'non-verbal' or 'minimally verbal'. Until very recently at least, such victims have largely remained invisible to both researchers and criminal justice professionals. ${ }^{5}$ At the outset, it is worth clarifying what these labels mean, given that they are contested terms across different disciplines (including speech therapy, education studies and psychology). ${ }^{6}$ For present purposes, we define a non-verbal witness as one who does not have enough command of any language system (oral/spoken, signed or technology-mediated) to deliver verbal evidence fluently and would require significant communication support such as the provision of a limited selection of picture symbols to indicate meaning and/or the support of a communication partner. This is likely to arise from autism, severe learning disabilities (SLD) or profound and multiple learning disabilities (PMLD) which may stem from an acquired brain injury or from a genetic, congenital or neurological impairment. ${ }^{7}$ Our working definition therefore does not encompass disabled witnesses who have access to a complex language system which provides a comparable equivalent to oral testimony such as Deaf witnesses (since British Sign Language is a language system in its own right) or witnesses with motor neurone disease and high cognitive functioning who can produce fluent accounts through an electronic communication device. Rather, our focus is on witnesses who have limited language (through any medium) and will require significant support including

3 Juan Bornman et al, 'Identifying Barriers in the South African Criminal Justice System: Implications for Individuals with Severe Communication Disability' (2016) 29 Acta Criminologica 12.

4 Deirdre Brown and Charlie Lewis, 'Competence is in the Eye of the Beholder: Perceptions of Intellectually Disabled Child Witnesses' (2013) 60(1) International Journal of Disability Development and Education 3; Gill Green, 'Vulnerability of Witnesses with Learning Disabilities: Preparing to Give Evidence against a Perpetrator of Sexual Abuse' (2001) 29(3) British Journal of Learning Disability 103-9; Lucy Henry et al, 'Perceived Credibility and Eyewitness Testimony of Children with Intellectual Disabilities' (2011) 55(4) Journal of Intellectual Disability Research 385; Helen Westcott and David Jones, 'Annotation: The Abuse of Disabled Children' (1999) 40 Journal of Child Psychology and Psychiatry 497.

5 Notable exceptions are a range of studies relating to non-verbal participants in the South African criminal justice system. See Bornman et al (n 3); Diane Bryen and Christopher Wickman, 'Ending the Silence of People with Little or No Functional Speech: Testifying in Court. (2011) 31 Disability Studies Quarterly <http://dsqsds.org/article/view/1711 on 30/06/17>; Robyn White et al, 'Testifying in Court as a Victim of Crime for Persons with Little or No Functional Speech: Vocabulary Implications' (2015) 16 Child Abuse Research in South Africa 1.

6 Catherine Lord et al, 'The Autism Diagnostic Observation Schedule - Generic: A Standard Measure of Social and Communication Deficits Associated with the Spectrum of Autism' (2000) 30(3) Journal of Autism and Developmental Disorders 205.

7 For instance, approximately $30 \%$ of people with a diagnosis of autism spectrum disorder are non-verbal or minimally verbal, with 'minimally verbal' denoting no more than 20-30 spoken words: Helen Tager $\square$ Flusbergand Connie Kasari, 'Minimally Verbal School-aged Children with Autism Spectrum Disorder: The Neglected End of the Spectrum' (2013) 6(6) Autism Research 468. Occasionally, some forms of dementia may also result substantial language loss: Hans Förstl and Alexander Kurz. 'Clinical Features of Alzheimer's Disease’ (1999) 249(6) European Archives of Psychiatry Clinical Neurosciences 288. 
symbolisation of words and/or communication partner support so they can access participatory rights on an equal footing.

Drawing on recent developments to support vulnerable witnesses in the criminal process of England and Wales, we undertake a thematic analysis of the nature of these participatory barriers and how they might be overcome. The most obvious starting point concerns the question of communication. Verbal interaction is the norm in most such settings - and the principle of orality has long been considered part of the bedrock of adversarial trial. ${ }^{8}$ We aim to explain the various alternative forms of voice for those who do not communicate verbally, outlining how Augmentative and Alternative Communication (AAC) offers an auspicious mechanism that can enable meaningful interaction using approaches such as picture exchange communication systems (PECS), Makaton signing, or speech-generating devices (SGDs). ${ }^{9}$ We analyse some of the positive developments that have occurred in relation to facilitating such witnesses and the opportunities that lie ahead, and the valuable role that intermediaries and aids to communication can play in facilitating these.

Having highlighted the ways in which voice might be exercised, the second part of the article explores the issue of competency. Some witnesses with severe learning difficulties will not be deemed capable of giving intelligible evidence and, as such, will be considered incompetent to testify. However, recent years have seen a more enlightened approach from the courts in determining such matters; and many non-verbal witnesses may now be deemed competent to testify.

The final part of the article turns to the issue of credibility. The evidence of learning disabled witnesses has long been viewed through a lens of suspicion, and as noted above, this goes some way to explaining the high attrition rate. It is suggested that negative perceptions of credibility are further compounded by the use of an atypical means of communication which, when aggravated by the structural deficiencies of the adversarial model of proof, means that justice is often denied for some of the most vulnerable in society.

\section{Communication}

The effectiveness and responsiveness of the public prosecutions system hinges upon vulnerable voices being heard and being taken seriously. The question then arises as to how the 'best evidence' of such witnesses can be best facilitated. Evidently, non-verbal victims face a unique challenge in this regard since they do not express themselves verbally.

\section{ALTERNATIVE FORMS OF VOICE}

One possible mechanism that might empower witnesses to interact more effectively with the criminal justice system is AAC. AAC refers to a burgeoning area of educational and clinical practice which aims to provide a range of communication methods to supplement or replace a person's natural speech and which is generally acknowledged to have emerged as recognised professional specialisation in the 1980s. ${ }^{10}$ Three of the most common

8 Patrick Devlin, The Judge (OUP 1979) 54.

9 Kieron Sheehy and Hester Duffy, 'Attitudes to Makaton in the Ages on Integration and Inclusion' (2009) 24(2) International Journal of Special Education 91; Sue Roulstone et al, 'Interventions for Children with Speech, Language and Communication Needs: An Exploration of Current Practice' (2012) 28(3) Child Language Teaching and Therapy 325.

10 Ralf Schlosser et al, 'Speech Output and Speech-generating Devices in Autism Spectrum Disorders' in Pat Mirenda and Teresa Iacono (eds), Autism Spectrum Disorders and AAC (Brookes 2009); Carole Zangari et al, 'Augmentative and Alternative Communication: An Historic Perspective' (1994) 10(1) Augmentative and Alternative Communication 27. 
methods of communication support which fall within the umbrella term AAC include SGDs (also known as voice-output communication aids or VOCAs) which may be operated by hand or through eye-gaze recognition technology; the use of symbol/picture cards; and the use of simplified manual signing systems designed for people with learning disabilities such as Makaton which draw upon the vocabulary of signed languages such as British Sign Language but which have significantly less grammatical complexity. ${ }^{11}$ However, a rich diversity of other methods also exists -including the use of writing and drawing, the use of artefacts such as dolls to re-enact scenarios - and any approach which aims to facilitate communication by supplementing or replacing natural speech with alternative mediums may be said to constitute a form of AAC.

It would be a mistake to think of 'AAC users' as a homogeneous group of witnesses as there will be wide variations in a range of factors, both individual and environmental, which will subsequently influence their communication output. A useful model for conceptualising this interplay of factors is the biopsychosocial model of disability recommended by the World Health Organization's International Classification of Functioning, Disability and Health or ICF. ${ }^{12}$ This biopsychosocial model conceptualises dis/ability as an emergent property of the interplay between individual impairment and environmental barriers and facilitators. According to this model, therefore, the successful facilitation of testimony by an AAC user would need to take account of both the user's individual characteristics and the extent of environmental communication barriers and facilitators. Individual variables might include: level of cognitive functioning; degree of mastery of chosen communication mediums; level of physical independence in operating AAC; level of social/emotional support and encouragement required; and psychological factors such as the individual's degree of confidence and motivation in using AAC generally, as well as their level of resilience to the stress of giving evidence. Environmental factors (in the immediate courtroom context) might include: the experience and knowledge of the intermediary appointed to support the user; the suitability of the AAC provision which is put in place; the extent and limitations of the vocabulary set provided by that AAC; and the degree to which the person's needs are effectively identified and met in relation to issues such as clear questioning techniques and minimisation of sensory distractions. Finally, more distal environmental factors come into play such as the witness's prior experience of AAC through education settings and/or speech and language therapy services. A witness who has their own familiar and well-established AAC system (whether that be embedded and extensive knowledge of Makaton signing or their own SGD in everyday usage) has the advantage over a witness who has only recently been introduced to $\mathrm{AAC}$ as part of the evidence-giving process; and a witness who is already familiar with sign or symbol vocabulary sets relevant to (for example) sexual abuse such as private body parts will be further advantaged. This complex interplay of factors will produce a diverse range of AAC users, from those who can convey basic short messages such as yes/no or 1-2 word phrases to users who can rapidly and confidently combine symbols or signs to answer a range of questions.

It is important to clarify the distinction between AAC and facilitated communication (FC). FC is a controversial technique which involves a facilitator supporting a person to spell out messages on an alphabet board through any combination of physical support to the person's arm or hand; verbal prompts and moral support, often producing startling outcomes of fluent, highly literate communication where communication ability of this level had not been evidenced previously. FC has a controversial history in the courtroom,

11 Roulstone et al (n 9); Sheehy and Duffy (n 9).

12 World Health Organization, International Classification of Functioning, Disability and Health, res 54.21 (2001). 
having been implicated in multiple instances of sexual abuse allegations which were subsequently found to be untrue, with authorship suspected to lie with the facilitator. ${ }^{13}$ FC is not accepted as a legitimate AAC intervention by the International Society for Augmentative and Alternative Communication, ${ }^{14}$ and its troubling courtroom history makes it worthy of mention for two reasons: firstly, to raise awareness of the possibility that jury perceptions of 'validity' and 'authorship' of AAC-mediated evidence more generally may be compromised by the history of FC in particular; and secondly to highlight the need for further unpacking of the different dimensions of support offered by intermediaries (social, emotional, organisational, communicative, physical) and the implications of these for perceived validity and authorship. These questions are discussed further below.

The technologies outlined above have undoubtedly empowered voices that have long gone unheard in a range of social settings. While the use of these technologies is relatively novel within criminal justice, and there are few reported cases on their use in legal settings, ${ }^{15}$ there is a growing body of evidence that such aids are becoming much more commonplace. ${ }^{16}$ The evidence gathered within other social settings suggests that, if properly used, AAC holds the potential to empower non-verbal victims through reducing levels of stress and facilitating them to give best evidence.

\section{FACILITATING COMMUNICATION}

The main statutory framework that assists non-verbal victims is contained in Part II of the Youth Justice and Criminal Evidence Act 1999 (YJCEA). ${ }^{17}$ Under s 16, any witness whose quality of evidence is likely to be diminished because, inter alia, they have a significant impairment of intelligence and social functioning is presumed to be eligible for a special measures direction. The court must satisfy itself that the special measure or combination of special measures is likely to improve the quality of the witness's evidence in terms of 'completeness, coherence and accuracy'. ${ }^{18}$ In total, eight such measures are set out in ss 23 to 30 of the Act. Ordinarily, witnesses with learning disabilities may expect to receive the benefit of pre-recorded evidence and the use of a televised link for the purposes of cross-examination in chief, ${ }^{19}$ and advocates and judges may remove wigs and gowns. ${ }^{20}$ Often, measures such as removal of wigs and gowns and the use of a live link or pre-recorded examination-in-chief are unlikely to be particularly contentious. One of

13 See, generally, John Jacobson et al, 'A History of Facilitated Communication: Science, Pseudoscience, and Antiscience Science Working Group on Facilitated Communication' (1995) 50(9) American Psychologist 750; Jason Travers et al, 'Facilitated Communication Denies People with Disabilities their Voice' (2014) 39(3) Research and Practice for Persons with Severe Disabilities 195.

14 Susan Balandin, 'ISAAC Position Statement on Facilitated Communication' (2014) 30(4) Augmentative and Alternative Communication 357.

15 An exception can be located in R $v$ Watts [2010] EWCA Crim 1924, where one witness was entirely incapable of speech or any other form of communication and where evidence from one non-verbal witness was facilitated through eye gaze technology and an electronic communication device. Her ABE interview was admitted under s 116(2) Criminal Justice Act 2003 as an exception to the hearsay rule.

16 See, generally, Joyce Plotnikoff and Richard Woolfson, Intermediaries in the Criminal Justice System (Policy Press 2015).

17 Special measures are not, however, available to defendants. A live link may be made available in certain circumstances under YJCEA, s 33A. Intermediaries may also be used in 'rare' cases for defendants: Criminal Practice Directions (Crim PD) (Amendment No 1) [2016] EWCA Crim 97. See further Laura Hoyano and Angela Rafferty, 'Rationing Defence Intermediaries under the April 2016 Criminal Practice Direction' (2017) Criminal Law Review 93.

18 YJCEA, ss 16(5) and 19(2).

19 Ibid ss 27 and 24 respectively.

20 Ibid s 26. 
the most radical measures is contained in s 28 of the YJCEA, which provides for the cross-examination and re-examination of the witness in advance of the trial. Receipt of the entire testimony of a vulnerable witness outside the formal courtroom environment in advance of the trial clearly holds the potential to significantly reduce fear and apprehension and to allow the witness to achieve some sense of closure within a relatively short time frame after the offence. However - citing concerns among the profession about its practical operation - the government declined to implement this provision when most of the other special measures came into force in July 2002. A pilot programme was eventually trialled at three Crown Court Centres at the end of 2013, but at the time of writing the prospect of national implementation remains uncertain. In terms of specific support for non-verbal witnesses that are currently available, two key provisions merit further consideration. Sections 29 and 30 provide for the use of intermediaries and the use of aids to communication respectively.

\section{Intermediaries}

Under s 29 of the Act, a court may order that an eligible witness may be examined through an independent intermediary in order to communicate:

... questions put to the witness, and to any persons asking such questions, the answers given by the witness in reply to them, and to explain such questions or answers so far as necessary to empowered them to be understood by the witness or person in question. ${ }^{21}$

Designed to assist witnesses with severe communication difficulties, intermediaries were first piloted in 2004, before a phased national roll-out began in 2008. The scheme has since made a significant impact on access to justice in cases which would never have previously gone to trial. ${ }^{22}$

Ordinarily, a non-verbal victim should be identified at an early stage in the investigative process, ${ }^{23}$ and at this stage the Achieving Best Evidence (ABE) process is triggered. ${ }^{24}$ The police and other criminal justice agencies should adhere to best practice guidelines laid down in respect of interviewing and questioning techniques to ensure that vulnerable witnesses are empowered to give their 'best' evidence. A registered intermediary, selected from a range of professionals with various skills sets, will then be matched with the witness by the National Crime Agency to assess the witness and make recommendations to various criminal justice personnel (such as police officers, advocates, judges and magistrates, Witness Service and court personnel) as to how the witness should be questioned. ${ }^{25}$ In many cases, this results in a video-recorded interview being used to substitute the child's live evidence-in-chief in court. ${ }^{26}$

21 YJCEA, s 29(2).

22 One evaluation estimated that more than half of cases evaluated would not have reached court without intermediary involvement: Joyce Plotnikoff and Richard Woolfson, The 'Go-between': Evaluation of Intermediary Pathfinder Projects (Ministry of Justice 2007).

23 In other cases, certain disabilities or other forms of vulnerability may not be so readily apparent. See further Brendan O'Mahony et al, 'The Early Identification of Vulnerable Witnesses Prior to an Investigative Interview' (2011) 13 British Journal of Forensic Practice 114.

24 Ministry of Justice, Achieving Best Evidence in Criminal Proceedings (Ministry of Justice 2011).

25 Penny Cooper and Michelle Mattinson, 'Intermediaries, Vulnerable People and the Quality of Evidence: An International Comparison of Three Versions of the English Intermediary Model' (2017) 21(4) 4 International Journal of Evidence and Proof 351; Plotnikoff and Woolfson (n 16).

26 Becky Milne and Ray Bull, 'Interviewing Victims of Crime, including Children and People with Intellectual Disabilities' in Mark R Kebbell and Graham Davies, Practical Psychology for Forensic Investigations and Prosecutions (John Wiley 2006). 
The initial assessment of a non-verbal victim by an intermediary should analyse the communicative capacities of the person concerned. This process can thus be used to identify users of AAC, the type of AAC technology relied upon, and the understanding, fluency and skill level of the user. This varies considerably from individual to individual. The intermediary is tasked with making 'recommendations as to special measures to enable the best communication', ${ }^{27}$ and the report should detail the ability and fluency of the AAC user and recommendations on what form of questions should be put to the witness. ${ }^{28}$ Often, questioners will be advised of ways to explain basic ground rules to witnesses such as 'Don't guess' or 'Tell the truth'. ${ }^{29}$ Although ABE interviews generally place emphasis on the need for free narrative, witnesses with learning difficulties may often require more structured and closed questions as many are reluctant to respond to open invitations. ${ }^{30}$ These recommendations will then be communicated to criminal justice professionals to inform decision-making about whether, and if so how, the investigation should proceed and a trial should be held. Where a case proceeds to trial, intermediaries will often attend a familiarisation visit with the witness and sit with the witness throughout proceedings. They are expected to monitor questioning and 'actively to intervene when miscommunication may or is likely to have occurred or to be occurring' (though their primary duty is to the court). ${ }^{31}$

Evidently, this represents a radical departure from the archetypal adversarial duel and 'vigorous and polarized' debates have taken place on intermediaries since they were first proposed by the Pigot Committee in 1989.32 Concerns have been expressed that the filtering of questioning could result in the loss of meaning, intonation and emphasis leading to questions as to how effective a defence the accused is able to mount in these circumstances. ${ }^{33}$ It also represents a threat to the long-standing principle of party control of evidence, ${ }^{34}$ and whether they are sufficiently equipped to identify and object to inappropriate lines of questioning. ${ }^{35}$ The risk of intermediaries 'overreaching' their role was addressed by the Court of Appeal in $R v$ Christian, ${ }^{36}$ where an intermediary put her arm around a witness when she became distressed, comforted her during her crossexamination, and asked counsel to moderate the tone of her voice. The judge instructed the jury not to allow sympathy for the complainant as a person to cloud their judgement of her as a witness. The appellant's concern that these actions interfered with the defendant's right to a fair hearing was dismissed; with the court stating that the question was not whether the intermediary had overstepped her proper role, but whether there was any serious risk of unfairness. Given the judicial direction, there was no sensible prospect of unfairness in the current case.

27 Ministry of Justice, Registered Intermediary Procedural Guidance Manual (Ministry of Justice 2012).

28 The report may cover other issues, such as how a witness might best be supported emotionally: Michelle Mattinson, 'Putting Theory into Practice: A Comparison of the Guidance Available to Investigative Interviewers and Advocates when using Communication Aids in the Criminal Justice System' in Penny Cooper and Linda Hunting (eds), Addressing Vulnerability in Justice Systems (Wildy, Simmonds and Hill 2016).

30 Plotnikoff and Woolfson (n 16) 90-1.

$31 \mathrm{R} v$ Cox [2012] 2 Cr App R 6, [28].

32 Lauran Hoyano and Caroline Keenan, Child Abuse Law and Policy across Boundaries (2007 OUP) 663.

33 Jonathan Doak, Victims' Rights, Human Rights and Criminal Justice: Reconceiving the Role of Third Parties (Hart 2008).

34 Emily Henderson “"A Very Valuable Tool” Judges, Advocates and Intermediaries Discuss the Intermediary System in England and Wales' (2015)19(3) International Journal of Evidence and Proof 154.

35 Laura Hoyano, 'Reforming the Adversarial Trial for Vulnerable Witnesses and Defendants' (2015) Criminal Law Reform 105.

36 [2015] EWCA Crim 1582. 
There are grounds for optimism in that many advocates now recognise that intermediaries can make a valuable contribution to decision-making processes, particularly concerning which cases to pursue and specific strategies that could be adopted to prevent miscommunication at trial. ${ }^{37}$ Interviews conducted with judges and advocates as part of a study by Emily Henderson in 2013 found widespread 'enthusiasm and warmth' for intermediaries, and that widespread fears over resistance from the profession had not materialised. ${ }^{38}$ Other studies have arrived at similar conclusions, and law reform bodies across the globe have also looked to the English model. ${ }^{39}$ While concerns remain that some advocates continue to hold reservations or lack the specialist knowledge that would enable them to conduct appropriate questioning, ${ }^{40}$ ongoing education and training may be capable of addressing this issue. ${ }^{41}$

\section{Aids to communication}

The use of an intermediary alone is unlikely to facilitate the evidence of non-verbal witnesses. In addition, such witnesses are likely to need the assistance of some form of AAC to express themselves. To this end, s 30 of the Act provides that the court may direct that a witness is permitted to use an 'aid to communication'; intermediaries will recommend which aids might improve communication on the basis of the individual needs of the witness. Aids to communication may thus not only enhance the quality of evidence, but may also reduce stress levels of the user. ${ }^{42}$ Oddly, no definition of what might constitute such an aid is provided in the legislation itself; anything deemed appropriate to the court is permissible although both the Equal Treatment Bench Book and the Criminal Procedure Rules (Crim PR) 2015 refer to an array of tools such as pictures, plans, symbols, dolls, figures, models, body maps and similar aids. ${ }^{43}$

On a practical level, however, concerns have been expressed that advocates and judges, in particular, are unfamiliar with the range of aids available and their potential to empower witnesses who lack verbal skills. There are some positive indications, however, that levels of understanding are improving. The Inns of Court College of Advocacy (formerly the Advocacy Training Council) has developed an online portal, The Advocate's Gateway, which is designed to offer evidence-based guidance to advocates, police officers, social workers, solicitors, guardians and judges who may encounter vulnerable witnesses or defendants at some point in their journey through the criminal justice system. ${ }^{44}$ Seventeen separate 'toolkits' are available and Toolkit 14: Using Communication Aids in the Criminal Justice System, is one of the few guidelines for advocates that make express

37 Joyce Plotnikoff and Richard Woolfson, 'Making Best Use of the Intermediary Special Measure' (2008) Criminal Law Reform 91.

38 Henderson (n 34) 168.

39 Cooper and Mattinson (n 25); Kirsten Hanna et al, Child Witnesses in the New Zealand Criminal Courts: a Review of Practice and Implications for Policy (NZ Law Foundation 2010); Plotnikoff and Woolfson (n 22); Jana Robinson 'The Experience of the Child Witness: Legal and Psychological Issues' (2015) 42 International Journal of Law and Psychiatry 168; Mary Woodward et al, 'Out of the Mouth of Babes: Enabling Children to Give Evidence in the Justice System' (2014) 39(1) Alternative Law Journal 27.

40 Henderson (n 34).

41 See below, p 461.

42 Plotnikoff and Woolfson (n 16), 69.

43 Judicial College, Equal Treatment Bench Book (Judicial College 2013); CPR 2015, r 3.9(7)(vi).

44 See further Mattinson (n 28). 
reference to the use of high-tech and low-tech forms of AAC outlined above. ${ }^{45}$ In addition to providing a lucid and informed outline of many of the forms of AAC, Toolkit 14 emphasises the importance of the role of the intermediary in assessing the verbal limitations or idiosyncratic speech patterns of a learning disabled witness and recommends a mixture of tools and strategies that might best facilitate the evidence of an individual witness.

The YJCEA has created a framework whereby evidence is much more likely to be received from non-verbal witnesses providing the competency test is met. Yet notwithstanding the introduction of special measures and greater numbers of witnesses with communication difficulties now being deemed competent to testify, fears have been expressed that 'the intimidatory and intrusive antics employed daily by defence lawyers in a range of contexts have escaped examination'. ${ }^{46}$ The onus then falls on the trial judge to militate against such tactics. ${ }^{47}$

\section{Judicial control}

Under the adversarial paradigm, judges have long been expected to exercise an 'umpireal' role and as such have been reticent to intervene to prevent oppressive advocacy lest $\mathrm{s} / \mathrm{he}$ be seen as 'descending from Avernus', 48 and 'entering the arena' in favour of one side or the other. ${ }^{49}$ Indeed, empirical research confirms judicial intervention to prevent excessive cross-examination of vulnerable parties has been relatively rare, ${ }^{50}$ although this may be partly attributable to the fact that until recently many have lacked the necessary knowledge about the needs of learning disabled witnesses in order to do so. ${ }^{51}$

Yet, in more recent times, it seems that the judiciary are rising admirably to this challenge, with the courts increasingly underlining the need for trial judges to take proactive steps to control the nature and substance of cross-examination. This metamorphosis of the judicial role has been spearheaded by the Court of Appeal in a line of decisions since 2011, and the court has made clear that it is incumbent on advocates to adapt their questioning so that it reflects the developmental needs of the witness. ${ }^{52}$ In Barker $^{53}$ it was stressed that advocates should adapt their 'forensic techniques' in order to enable best evidence. This should entail the use of 'short, simple questions which put the

45 The Advocates Gateway, Toolkit 14: Understanding Communication Aids in the Criminal Justice System (Council of the Inns of the Court 2015: <www.theadvocatesgateway.org>. These toolkits have been endorsed by the Court of Appeal in Lubemba [2015] 1 WLR 1579, 1581; Crim PD I [2015] EWCA Crim 1567, [3D.7].

46 Louise Ellison, The Adversarial Process and the Vulnerable Witness (OUP 2001) 125.

47 It is possible, however, that social stereotypes and prejudices that emanate from the demeanour of the witness may be neutralised to some extent through jury discussion: Janne Dahl et al, 'Displayed Emotions and Witness Credibility: A Comparison of Judgements by Individuals and Mock Juries' (2007) 21(9) Applied Cognitive Psychology 1145.

48 Sean Doran, 'Descent to Avernus' (1989) 139 New Law Journal 1147.

49 See comments of Stuart-Smith LJ in R $v$ Sharp [1993] 3 All ER 225, 231.

50 Emma Davies and Fred Seymour, 'Questioning Child Complainants of Sexual Abuse: Analysis of Criminal Court Transcripts in New Zealand' (1998) 5(1) Psychiatry, Psychology and Law 547; Caitriona O’Kelly et al, 'Judicial Intervention in Court Cases Involving Witnesses with and without Learning Disabilities' (2003) 8(2) Legal Criminological Psychiatry 229-40; Rachel Zajac et al, 'Disorder in the Courtroom? Child Witnesses under Cross-examination' (2012) 32(3) Developmental Review 181-204.

51 Mark Kebbell et al, 'People with Learning Disabilities as Witnesses in Court: What Questions Should Lawyers Ask?’ (2001) 29(3) British Journal of Learning Disability 98.

52 See further Emily Henderson, 'All the Proper Protections: The Court of Appeal Rewrites the Rules for the Cross-examination of Vulnerable Witnesses’ (2014) Criminal Law Review 108.

53 [2010] EWCA Crim 4. 
essential elements of the defendant's case to the witness', with any comment on credibility following after the testimony has concluded. ${ }^{54}$ Likewise, in $E,{ }^{55}$ it was stated that steps taken by trial judges to place limits on cross-examination would not ordinarily undermine the accused's right to a fair trial. Underlining the importance of the principle of equality of voice in Cox, ${ }^{56}$ Lord Judge CJ outlined the duty on trial judges to adapt proceedings to ensure that those with disabilities were not placed at a disadvantage:

[A]s part of their general responsibilities judges are expected to deal with specific communication problems faced by any defendant or any individual witness ... as part and parcel of their ordinary control of the judicial process. When necessary, the processes have to be adapted to ensure that a particular individual is not disadvantaged as a result of personal difficulties, whatever form they may take. ${ }^{57}$

More recently, it was held in Lubemba that trial judges are under a duty to intervene where cross-examination is confusing or inappropriate, and should set reasonable time limits. ${ }^{58}$ Moreover. this line of reasoning is reflected in the Lord Chief Justice's Criminal Practice Direction 2015 which provides:

The judiciary is responsible for controlling questioning. Over-rigorous or repetitive cross-examination of a child or vulnerable witness should be stopped. Intervention by the judge, magistrates or intermediary (if any) is minimised if questioning, taking account of the individual's communication needs, is discussed in advance and ground rules are agreed and adhered to. ${ }^{59}$

In practice, such limits on cross-examination are enforced through ground rules hearings (GRHs) which should be held before a child witness or any other witness with special communication needs gives evidence. Such hearings are mandatory in all cases involving intermediaries and recommended in others. ${ }^{60}$ The GRH should determine the nature and form of questioning that should be used where a vulnerable witness is cross-examined. A range of issues may be considered, including: the need to avoid repetitive questioning; controlling comment and accusations of lying; time limits on cross-examination; the type of vocabulary used in questioning; and the practicalities surrounding any intervention by the intermediary. ${ }^{61}$

While the powers and mechanisms to control the excesses of cross-examination have certainly been bolstered, scepticism has been expressed - often with good reason - that the working cultures of the legal profession and embedded practices of the adversarial tradition often stymie the reach of well-intentioned reform. ${ }^{62}$ Ultimately, the success or failure of these changes hangs upon the extent to which practitioners, and in particular the judiciary, are prepared to embrace such a radical culture change; robust judicial case management is undoubtedly required to ensure that advocates understand and comply with legal and policy expectations. Somewhat disconcertingly, the track record of

54 Ibid [42].

55 [2011] EWCA Crim 3028. See also Wills [2012] 1 Cr App R 2.

$56 \operatorname{Cox}(\mathrm{n} 30)$.

57 Ibid [29].

58 Lubemba (n 44).

59 Crim PD I, 3E.1 [2015] EWCA Crim 1567.

60 See Crim PR 3.9(7); Crim PD I, 3E.2 (2015); R v JP [2014] EWCA Crim 2064. See further Penny Cooper et al, 'Getting to Grips with Ground Rules Hearings - a Checklist for Judges, Advocates and Intermediaries' (2015) Crim LR 417 (noting that forms of GRHs were occurring as early as 2006).

61 Ibid.

62 Doak (n 33); Ellison (n 46); Matthew Hall, Victims of Crime: Policy and Practice in Criminal Justice (Willan 2009). 
advocates (and to a lesser extent, judges) in embracing such reforms aimed at improving the experiences of vulnerable witnesses is not particularly encouraging. ${ }^{63}$

Given that AAC constitutes such a radical departure from the emphasis that has traditionally been placed on ebb and flow of adversarial advocacy, there may be good reason to question whether it might ever become embedded as a norm of communication. That said, there is evidence that attitudes are shifting. In a qualitative study in 2013 involving interviews with criminal advocates experienced in sex cases, Henderson found 'a more sophisticated understanding of the language issues' than that of advocates interviewed 15 years previously, ${ }^{64}$ and also found a genuine desire to improve practice and adopt innovation even where this conflicted with embedded traditions. Despite these positive overtones, the research concluded that the majority of cross-examiners lack the skills and specialist training to cross-examine vulnerable witnesses. ${ }^{65}$ Other studies have arrived at similar conclusions, ${ }^{66}$ and have also identified a lack of understanding by other criminal justice professionals. ${ }^{67}$ Evidently, without such training many advocates would be ill-placed to know what constitutes an inappropriate question or how to elicit comprehensible responses from a non-verbal witness.

\section{Competency}

Of course, the AAC technologies discussed above will only be of value where a witness is deemed competent to testify. Historically, there has been significant suspicion around the evidence of those with communication difficulties; ${ }^{68}$ only a few decades ago strict exclusionary principles were applied in relation to the testimony of children ${ }^{69}$ or those living with a mental illness. ${ }^{70}$ Section 53 of the YJCEA provides for a presumption of competency in respect of all witnesses though this is rebuttable where a party can show that a witness is unable to understand questions or give answers that cannot be understood. ${ }^{71}$ Whilst a learning disability involving a severe language impairment may not in itself preclude a witness from testifying, it could provide grounds for one party to query competence, in which case the party calling the witness is required to prove that

63 See e.g. Antonia Cretney and Gwynn Davis, 'Prosecuting Domestic Assault: Victims Failing Courts, or Courts Failing Victims?' (1997) 36(2) Howard Journal 146; Emma Davies et al, 'In the Interests of Justice? The Crossexamination of Child Complainants of Sexual Abuse in Criminal Proceedings' (1997) 4 Psychiatry, Psychology, and Law 217; Ellison (n 46); Louise Ellison and Vanessa Munro, 'Taking Trauma Seriously' (2017) 21(3) International Journal of Evidence and Proof 183; Emily Henderson, 'Communicative Competence? Judges, Advocates and Intermediaries Discuss Communication Issues in the Cross-examination of Vulnerable Witnesses' [2015] Criminal Law Review 659; O’Kelly et al (n 50); Jennifer Temkin, 'Prosecuting and Defending Rape: Perspectives from the Bar.' (2000) 27(2) Journal of Law and Society 219-48; Helen Wescott, 'Child Witness Testimony: What Do We Know and Where Are We Going?’ (2006) Child and Family Law Quarterly 175.

64 Henderson (n 63).

65 Ibid 676.

66 Nicholas Bala, 'Child Witnesses in the Canadian Criminal Courts: Recognizing their Capacities and Needs' (1999) 2 Psychology, Public Policy and the Law 323; Emily Henderson, 'Persuading and Controlling: The Theory of Cross-examination in Relation to Children' in Helen Westcott et al (eds), Children's Testimony: A Handbook of Psychological Research and Forensic Practice (John Wiley \& Sons 2002); Kebbell et al (n 51); Zajac et al (n 50).

67 Katie Maras et al, 'Autism in the Courtroom: Experiences of Legal Professionals and the Autism Community' (2017) 47(8 Journal of Autism and Developmental Disorders 2610.

68 See, generally, John R Spencer and Michael Lamb (eds), Children and Cross-examination: Time to Change the Rules? (Bloomsbury 2012).

$69 \mathrm{R} v$ Wallwork [1958] $42 \mathrm{Cr}$ App R 153.

$70 \mathrm{R} v$ Bellamy (1986) $82 \mathrm{Cr}$ App R 222. Indeed, it was formerly the case that the witness had to believe in some form of divine sanction: Attorney General v Bradlaugh (1885) 14 QBD 667.

71 YJCEA, s 53(3). 
$\mathrm{s} /$ he is able to communicate intelligibly on the balance of probabilities. ${ }^{72}$ In practice, any issues around competency of a witness will be identified at an early stage in the process, and the court may question the witness, consider expert evidence, and evaluate extracts from the recording of the $\mathrm{ABE}$ interview as part of any competency hearing. Any determination reached at that point in the process may be revisited by the trial judge after cross-examination. ${ }^{73}$

In recent times the higher courts have made clear that testimony ought to be received where possible, even if this would involve a radical departure from the traditional oral hearing. In $R v$ Watts, ${ }^{74}$ the complainant had cerebral palsy and was only capable of uttering a few limited words. As the Court of Appeal noted, the parliamentary intention underpinning the 1999 Act is that those who are competent to give evidence should be assisted to do so. ${ }^{75}$ The court has also stressed that fulfilment of the competency requirement does not hinge upon the ability of the witness to offer detailed or intelligible replies to all questions; rather the court should look to form an overall impression. ${ }^{76}$ This view was echoed in Barker, ${ }^{77}$ where the court drew an important distinction between competency and credibility. While the former was a question of intelligibility, the latter was a question of weight for the jury. ${ }^{78}$ Thus, there should be no 'implicit stigma' relating to child witnesses, and nor should children be regarded as inherently less reliable. For Hallet LJ, it is essentially reduced to the principle of equal access to justice:

The purpose of the trial process is to identify the evidence which is reliable and that which is not, whether it comes from an adult or a child. If competent, as defined by the statutory criteria, in the context of credibility in the forensic process, the child witness starts off on the basis of equality with every other witness. In trial by jury, his or her credibility is to be assessed by the jury, taking into account every specific personal characteristic which may bear on the issue of credibility, along with the rest of the available evidence. ${ }^{79}$

Although these remarks were made in the context of child witnesses, it is evident that they also apply to witnesses with learning disabilities:

These statutory provisions are not limited to the evidence of children. They apply to individuals of unsound mind. They apply to the infirm. The question in each case is whether the individual witness, or, as in this case, the individual child, is competent to give evidence in the particular trial. ${ }^{80}$

Moreover, whilst factors such as age and the nature and extent of any learning disability ought to be taken into account, these should not be determinative and the ultimate question for the court to determine is whether the evidence as a whole is intelligible:

The question is entirely witness or child specific. There are no presumptions or preconceptions. The witness need not understand the special importance that the truth should be told in court, and the witness need not understand every single question or give

72 Ibids 54(2).

73 R v Malicki [2009] EWCA Crim 365; Police and Criminal Evidence Act 1984, s 78, may be used as a basis on which to exclude evidence where the witness is deemed incompetent following cross-examination.

74 Watts (n 15).

75 Ibid [18].

$76 \mathrm{R} v$ Sed [2004] 1 WLR 3218; DPP $v$ R [2007] EWHC 1842.

77 Barker (n 53).

78 See also Watts (n 15); R v Macpherson [2006] 1 Cr App R 30.

79 Barker (n 53) [40]. The primacy of the jury is the trier of fact was also mentioned in a similar context in Watts (n 15) [54]. See below, pp 466-7.

80 Barker (n 53) [38]. 
a readily understood answer to every question. Many competent adult witnesses would fail such a competency test. Dealing with it broadly and fairly, provided the witness can understand the questions put to him and can also provide understandable answers, he or she is competent. 81

The rules introduced by the 1999 Act governing the competency of witnesses are of symbolic, as well as practical, importance. As Spencer notes:

$[T]$ he rules 'mark the final transition from a system where the courts refused to hear all sorts of persons for fear they might not tell the truth, to one where the courts listen to everybody, and try to decide whether they are truthful or not on the basis of what they have said'. 82

The judicial plasticity regarding the competency requirements has enabled many more witnesses with learning disabilities, including non-verbal victims, to give evidence in recent years. It is also consistent with psychological evidence regarding the capacity of learning disabled witnesses to give reliable evidence. Providing the witness is equipped with the correct tools to understand questions and give intelligible answers, there are no grounds for a blanket policy exclusion. ${ }^{83}$ Even where witnesses are deemed not to be competent, potentially, a hearsay statement may be admitted where the court deems that the interests of justice require it ${ }^{84}$ (competency is not a precondition in such instances). ${ }^{85}$ However, even where many non-verbal witnesses are considered competent, fears around how juries will perceive the credibility of such witnesses impede the prospects of many such cases reaching trial and there is evidence to suggest that the Crown Prosecution Service has traditionally exercised caution in proceeding. ${ }^{86}$ In the section below, we seek to unpick some of the reasons why their testimonies are often viewed as suspect.

\section{Credibility: a problem of perception}

Manifestations of learning disabilities - mostly around communication and social function - sometimes result in certain witnesses being perceived as less credible or reliable. In particular, non-verbal individuals with autism may exhibit atypical forms of behaviour in stressful environments such as poorly modulated eye contact, unusual body movements (e.g. rocking, hand-flapping or clapping), hesitation in answering questions and odd vocal responses (e.g. echolalia or random sounds). These may negatively affect how a non-verbal witness is perceived by both criminal justice professionals (such as police officers, prosecutors, advocates or intermediaries) and, where the case proceeds to trial, the judge and jury. ${ }^{87}$

Such cues may give the impression that a witness is being deceptive, less sincere, or uncertain of the facts, though this erroneous and widely held assumption has been

81 Ibid. See also DPP $v$ R [2007] EWHC Crim 1842; R $v$ LA and Others [2013] EWCA Crim 1308.

82 John Spencer, 'The Youth Justice and Criminal Evidence Act 1999: The Evidence Provisions' (2000) Jan Arch News 5.

83 Brown and Lewis ( $\mathrm{n}$ ).

84 Criminal Justice Act 2003, s 114(1)(d).

$85 \mathrm{R} v \operatorname{Sed}$ (Ali Dabir) [2004] EWCA Crim 1294.

86 House of Commons, Justice Committee, Ninth Report, The Crown Prosecution Service: Gatekeeper of the Criminal Justice System (2009 HMSO) 43; Andrew Sanders et al, Victims with Learning Disabilities: Negotiating the Criminal Justice System (Home Office Research Findings No 44, Home Office 1996).

87 Alicia Hall et al, 'Criminal Justice Issues and Autistic Disorder' in Robin Gabriels and Dina Hill (eds), Growing Up with Autism: Working with School Age Children and Adolescents (Guilford Press 2011) 285-6. 
comprehensively rebutted by psychological research. ${ }^{88}$ Even if the prosecution believes that the witness is likely to pass the competency threshold, the prosecution may still not proceed if it is determined that the likelihood of a conviction is reduced by how the witness may perform in court.

The secrecy surrounding jury deliberations means that it is difficult to discern the impact of certain idiosyncratic behaviours on jury decision-making. ${ }^{89}$ However, research based around mock juries, as well as evidence from other jurisdictions, suggests there is strong evidence that witnesses with learning disabilities are less likely to be believed in giving evidence (although there is no specific existent research on perceptions of AAC users). ${ }^{90}$ Various 'testimonial factors' are said to affect credibility, such as perception, memory, communication and sincerity; ${ }^{91}$ and even others that have clearly no relevance whatsoever, such as 'attractiveness', have been documented as factors taken into account. ${ }^{92}$ However, it has been established that although those with learning difficulties may recall less detail in response to open-ended questions than neurotypical witnesses, ${ }^{93}$ the accuracy of their recall is generally high although their answers may be perceived as vague or confused. ${ }^{94}$ Henry et al found that many mock jurors noted how they appeared to be distracted or disinterested. ${ }^{5}$ Overall, there seems to be a discrepancy between the ability of such witnesses to offer accurate testimony and jurors' perceptions of their ability. ${ }^{96}$

Learning disabled witnesses are also much more likely to be open to suggestion when questioned by authority figures in unfamiliar environments. ${ }^{97}$ In turn, they are more likely to acquiesce and provide the answer that they believe the questioner is seeking as opposed to attempting accurate recall. ${ }^{98}$ Or they may simply comply in order to escape the confines of a stressful setting. ${ }^{99}$ These risks are particularly pertinent at both the investigative and trial stages of the criminal process, where evidence confirms that high stress levels, coupled with inappropriate questioning techniques, may negatively affect the ability of vulnerable witnesses to recall past events accurately. ${ }^{100}$ Stereotyping and biases against AAC users may be even more prominent given that there appears to be a

88 Michael Green, ‘Credibility Contests: The Elephant in the Room' (2014) 18(1) International Journal of Evidence and Proof 28; Rebecca Nathanson and Michelle Platt, 'Attorneys' Perceptions of Child Witnesses with Mental Retardation' (2005) 33(1) Journal of Psychiatry and Law 5.

89 Ellison and Munro (n 63).

90 Henry et al (n 4); Georgina Stobbs and Mark Kebbell, 'Jurors' Perception of Witnesses with Intellectual Disabilities and the Influence of Expert Evidence' (2003) 16(2) Journal of Applied Research in Intellectual Disabilities 107.

91 Helene Love, 'Aging Witnesses: Exploring Difference, Inspiring Change' (2015) 19(4) International Journal of Evidence and Proof 210-27.

92 Stobbs and Kebbell (n 90).

93 Gisli Gudjonsson and Lucy Henry, 'Child and Adult Witnesses with Intellectual Disability: The Importance of Suggestibility (2003) 8 Legal Criminological Psychiatry 241; Stobbs and Kebbell (n 90).

94 Sarah Agnew and Marine Powell 'The Effect of Intellectual Disability on Children's Recall of an Event across Different Question Types' (2004) 28 Law and Human Behaviour 273; Brown and Lewis (n 4); Lucy Henry and Gisli Gudjonsson, 'Eyewitness Memory, Suggestibility and Repeated Recall Sessions in Children with Mild and Moderate Intellectual Disabilities’ (2003) 27 Law and Human Behaviour 481.

95 Henry et al (n 4).

96 Stobbs and Kebbell (n 90).

97 Gudjonsson and Henry (n 93); Mattinson (n 28).

98 Kim Drake, 'The Psychology of Interrogative Suggestibility: A Vulnerability during Interview' (2010) 49 Personality and Individual Differences 683.

99 Brendan O'Mahony, 'How Effective are Judges and Counsel at Facilitating Communication with Vulnerable Persons in a Criminal Trial?' in Cooper and Hunting (n 28).

100 See e.g. Green (n 4); Milne and Bull (n 26). 
correlation between perceived maturity and credibility. ${ }^{101}$ In other words, the sharp contrast between the communicative style of a learning disabled AAC user against the expectation of how a neurotypical witness of the same age should communicate might further undermine credibility.

In addition, these erroneous indicators of credibility are often exacerbated by the impact of trauma which by itself may negatively impact upon memory recall and be wrongly interpreted as an indicator of mendacity. ${ }^{102}$ As Ellison and Munro highlight, trauma victims often live with fragmented memories, lacking in specific detail and framed without a linear narrative. ${ }^{103}$ As the impact of trauma on memory recall is not widely known, the authors contend that jurors ought to be provided with this information in order to inform their decision making. ${ }^{104}$

A further dimension of credibility turns on how the presence of an intermediary and/or AAC provision could influence the court's perception of the 'validity' and 'authorship' of the evidence. By 'validity', we refer to the extent to which the expressed message is deemed to reflect what the witness wished to convey to the court; and by 'authorship' we refer to the extent to which the expressed message is deemed to have been constructed by the witness themselves. With regard to validity, questions might arise around the size of the symbol/signed vocabulary set used by the witness and whether limited vocabulary might give rise to approximated and misleading meanings (for instance, the verb 'touch' has a plethora of related verbs such as 'grab' and 'caress' with very different connotations of intensity, intention and reciprocity). Similarly, given the unfortunate history of $\mathrm{FC}$ in the courtroom, ${ }^{105}$ combined with the clearly visible support from an intermediary and/or communication device, questions could arise about the extent to which the witness independently authored the AAC-mediated message of their own volition. Toolkit 14 does not explicitly address this issue in its advice to intermediaries, seemingly working on the assumption that the witness will physically produce their own communication output through (for example) signing or independent manual operating of a device; and that the various elements of intermediary 'good practice' recommended, such as pointing to timelines or translating unclear speech for the court, will not compromise perceptions of 'authorship' in any way.

We are conscious that even discussing the very concepts of 'validity' and 'authorship' of AAC-mediated evidence runs the risk of what Ashby describes as the 'othering' that takes place when a particular (disabled) group is made the subject of special scrutiny in a way that non-disabled people are not. ${ }^{106}$ This concern is relevant in the current context: we would argue that AAC users are not categorically different from verbal witnesses whose oral 'validity' or 'authorship' might be compromised by any number of factors, including limited vocabulary; low educational level; susceptibility to stress; or acquiescence to the suggestions of an aggressive cross-examiner. On this basis, 'validity' and 'authorship' concerns should thus be dealt with on an ad hoc basis rather than in the form of presumptions about whole categories of witnesses. At the same time, it seems preferable to explicitly acknowledge that AAC may give rise to particular concerns around

101 Henry et al ( $\mathrm{n} 4)$.

102 Ellison and Munro (n 63).

103 Ibid.

104 Again, the courts have been proactive in facilitating this: see R $v$ Doody [2008] EWCA Crim 2394 (regarding the impact of trauma on the testimony of a rape victim).

105 See Balandin (n 14); Jacobson et al (n 13); Travers et al (n 13).

106 Christine Ashby, "Whose "Voice" Is It Anyway?: Giving Voice and Qualitative Research Involving Individuals that Type to Communicate' (2011) 31(4) Disability Studies Quarterly. 
'validity' and 'authorship' in the minds of jurors, advocates and others who are unfamiliar with its usage, rather than leaving this as a dangerous unconscious prejudice. Further, theoretical unpacking of this issue may be necessary to explore (for example) whether providing jurors with reports on an AAC user's typical communicative style and repertoire would help to challenge unfounded assumptions on the basis of appearances and encourage rational, conscious evaluation of likely validity and authorship; or alternatively further stigmatise AAC users by problematising issues which are not generally raised in the case of speaking witnesses.

Yet, as suggested above, the greatest single barrier to the issue of credibility is located within the confines of the adversarial paradigm itself. The belief in the primacy afforded to oral evidence has informed the evolution of the rules of criminal procedure and evidence for centuries. ${ }^{107}$ There is something of an inbuilt perception that oral forms of evidence are superior to other forms (such as written evidence or 'real' evidence); thus adversarial proceedings have placed a strong emphasis on the proper use of articulate and detailed oral accounts that can be readily challenged through cross-examination in court. Accounts that appear confused, disjointed and inarticulate are portrayed as untrustworthy; little allowance has been afforded to pertinent questions posed by psychologists around the reliability of memory or the capacity for factual recall under stress. At every stage of the criminal process there is an inherent assumption that participants are verbally equipped to report offences, explain their actions, and answer questions to aid the investigative and trial processes.

It is well documented that the nature of the adversarial trial is a source of secondary victimisation for many victims and witnesses, ${ }^{108}$ but the sequelae are significantly exacerbated among those who live with learning difficulties, some of whom will have minimal understanding of its nature and function. ${ }^{109}$ In particular, the convoluted and unfamiliar language of the courtroom, coupled with the use of forensically tuned linguistic devices adopted by cross-examiners, have been widely decried as mechanisms which are deliberately used to confuse and disorientate vulnerable witnesses. ${ }^{110}$ While the introduction of special measures and a more robust judicial stance on controlling of cross-examination have served to militate against some of the worst excesses of the adversarial trial, its structural orientation as an oral duel between prosecution and defence continues to discriminate against those least able to participate within this paradigm.

\section{ADDRESSING THE CREDIBILITY DEFICIT}

Two suggestions can be made in addressing issues pertaining to credibility. First, the wider use of expert evidence (particularly that of a psychologist or psychiatrist) may militate against negative perceptions of credibility and reliability. In particular, it could be used to explain that some of the manifestations of disability outlined do not equate to an inability to provide truthful and accurate evidence. ${ }^{111}$

107 Patrick Devlin, The Judge (OUP 1979) 54.

108 Doak (n 33); Ellison (n 46); Ellison and Munro (n 63); Green (n 4); Henderson (n 63).

109 Sanders et al (n 86); White et al (n 5).

110 Mark Brennan and Roslin Brennan, Strange Language: Child Victims under Cross-Examination (Wagga Wagga, 1988); Mark Kebbell et al, 'Lawyers' Questioning: The Effects of Confusing Questions on Witness Confidence and Accuracy' (2000) 24 Law and Human Behaviour 629; Zajac et al (n 50).

111 Stobbs and Kebbell (n 90). 
Unfortunately, there is a longstanding rule that expert evidence pertaining to issues of credibility is generally inadmissible. ${ }^{112}$ Thus, in $\mathrm{R} v$ Robinson ${ }^{113}$ the Court of Appeal held that the prosecution should not have been permitted to recall a psychologist to give evidence as to whether or not the complainant was suggestible and liable to fantasise; exceptions to the rule in Toobey only applied where the prosecution sought to pre-empt or rebut any suggestion by the defence that the evidence should be disregarded due to mental abnormality. On these grounds, Robinson was distinguished in $\mathrm{R} v S(\mathrm{VJ}),{ }^{114}$ where the appellant had been convicted of a range of sexual offences against a 13-year-old girl who had autism. A paediatrician gave evidence that the demeanour of the complainant in a video interview was not unusual for someone with autism, and, in general, autistic people would be highly unlikely to invent such a story and retain it in their memory. The appellant contended that this evidence was essentially an effort to boost credibility and, as such, should have been excluded. The appeal, however, was rejected on the grounds that the evidence was of generic application since it was a trait common to all people living with autism and did not pertain to the specific capabilities of a particular witness.

Although the clarification of the law in $S$ may assist non-verbal victims who live with a clinical label, this is not always the case and non-verbalism may be attributable to an unidentified or undiagnosed condition. ${ }^{115}$ The broader rule (i.e. prohibiting expert evidence of issues of credibility of a specific witness) has been roundly criticised on the grounds that 'the questions which it is important for a jury to decide for itself may be the very questions on which it most needs expert advice if it is to avoid serious injustice'.116 There appears to be a compelling case for reform; expert evidence is widely used to such ends in others jurisdictions 117 and it seems intuitively odd to adopt a stance whereby experts are unable to tailor their evidence to reflect the particular difficulties of individual witnesses.

An alternative (or additional) solution may lie in trial judges providing the jury with some direction on these matters. While judicial warnings have long been commonplace on matters such as suspect identification, delays in making sexual complaints, accomplice evidence, histories of false allegations and previous convictions, there is little evidence that they are issued regularly in respect of issues pertaining to demeanour and perceptions of credibility. ${ }^{118}$ In light of the expansive evidence that demeanour is a poor indicator of veracity, calls have been made for a mandatory demeanour warning, particularly in regard to evidence from vulnerable groups. ${ }^{119}$ The possibility was rejected by the New Zealand Court of Appeal in $E v R,{ }^{120}$ which seemed to prefer the historical practice for juries being free to evaluate demeanour as an indicator of credibility over the weight of social scientific evidence against it. From our perspective, however, is clear that

112 Toohey v Metropolitan Police Commissioner [1965] 1 All ER 506.

113 (1994) 98 Cr App R 370.

114 [2006] EWCA Crim 2389.

115 Sonja Vernes et al, 'Functional Genetic Analysis of Mutations Implicated in a Human Speech and Language Disorder’ (2006) 21(15) Human Molecular Genetics 3154.

116 Tony Ward, 'Usurping the Role of the Jury? Expert Evidence and Witness Credibility in English Criminal Trials' (2009) 13(2) E\&P 83, 100. See also Louise Ellison, 'Closing the credibility gap: the prosecutorial use of expert witness testimony in sexual assault cases’ (2005) 9(4) International Journal of Evidence and Proof 239; Ellison and Munro (n 63).

117 Ellison and Munro (n 63).

118 Robert Fisher, 'The Demeanour Fallacy' (2014) 14(4) NZLR 575.

119 Brown and Lewis (n 4); Fisher (n 118).

120 [2013] NZCA 678. 
such a mechanism holds the potential to address negative stereotyping in relation to learning disabled witnesses, particularly when the opportunities for experts to inform juries is so limited. ${ }^{121}$

\section{Conclusions}

Non-verbal victims, at least those who are capable of understanding basic questions and offering intelligible answers, are now afforded an opportunity not only to have their voices heard, but also to have those voices considered seriously at both the investigative and trial stages of the criminal process. In addition to these developmentally sensitive adjustments to law, policy and procedure, the courts have exercised considerable juridical vigour in facilitating the best evidence of atypical vulnerable witnesses, and the Advocates Training Council and Judicial College have also been proactive in promoting specialist education and training.

It is encouraging to see the legal profession demonstrate that it is open to challenging traditional assumptions about learning disabled witnesses and exhibit an openness towards reform. These changes will take some time to embed, and challenges still lie ahead in 'mainstreaming' alternatives to oral evidence. But it is anticipated that in the years ahead more non-verbal victims will feel able to exercise their voice and will receive appropriate support to convey their message, have the content of that message carefully considered, and, subsequently, exert an influence on the decision-making in both the investigative and trial phases of the criminal process. It is hoped, and expected, that in time this will boost reporting and conviction rates, and reduce attrition rates. While this article has focused on the trial process, some of the lessons set out here may inform future approaches concerning participation in other facets of the criminal process, such as requesting information about the case or challenging charging decisions. If this is accomplished, we are well on the road to establishing a more equal, legitimate and inclusionary criminal justice system where all witnesses are enabled to participate irrespective of their cognitive or developmental capabilities. 